\title{
Walking Football as sustainable exercise for older adults - a pilot investigation
}

Peter Reddy ${ }^{1}$, Irundika Dias ${ }^{1}$, Carol Holland ${ }^{1}$, Niyah Campbell ${ }^{1}$, laysha Nagar ${ }^{1}$, Luke Connolly ${ }^{2}$, Peter Krustrup ${ }^{3}$, Harry Hubball ${ }^{4}$.

${ }^{1}$ School of Life and Health Sciences, Aston Triangle, Aston University, Birmingham, B4 7ET, UK. +44 (0) 1212043000

p.a.reddy@aston.ac.uk

h.k.i.dias1@aston.ac.uk

c.holland1@aston.ac.uk

n.campbell3@aston.ac.uk

nagario@aston.ac.uk

${ }^{2}$ Sport and Health Sciences, Faculty of Life and Environmental Sciences, Exeter University, Exeter, EX1 2LU, UK. +44 (0) 1392722896

ljc219@exeter.ac.uk

${ }^{3}$ Department of Nutrition, Exercise and Sports (NEXS), Copenhagen Centre for Team Sport and Health, University of Copenhagen, Nørre Allé 51, DK-2200 Copenhagen N, Denmark. +45 353-21624

pkrustrup@nexs.ku.dk

${ }^{4}$ Department of Curriculum and Pedagogy, University of British Columbia, 2125 Main Mall, Vancouver, BC Canada V6T 1Z4. 6048225422

harry.hubball@ubc.ca

${ }^{1}$ Corresponding author: Peter Reddy, School of Life and Health Sciences, Aston University, Birmingham, B4 7ET, UK. +44 (0) 1212043000

p.a.reddy@aston.ac.uk 


\section{Abstract}

The health benefits of playing football and the importance of exercise and social contact for healthy ageing are well established, but few older adults in the UK take enough exercise. Football is popular, flexible in format and draws players into engrossing, effortful and social exercise, but the physical demands of play at full speed may make it unsustainable for some older adults. Restricted to walking pace, will play still be engaging? Will health benefits be retained? Will physical demands remain manageable? This pilot study aims to investigate: 1 ) The experience of older adults playing walking football every week, is it sustainable and rewarding, 2) the intensity and locomotor pattern of walking football, 3) the scale and nature of walking football health benefits, 4) possible cognitive benefits of playing walking football through measures of processing speed, selective and divided attention and updating and inhibition components of executive function. 'Walking football' and 'waiting list' groups were compared before and after 12 weeks of one-hour per week football. Walking football was found to be engaging, sustainable for older adults and moderately intensive, however, selective health and cognitive benefits were not found from this brief intervention.

\section{Key words:}

Ageing. Cognition. Exercise. Health. Team Sport

\section{Introduction}

Over 10 million people in the UK are aged over 65 and this may double by 2050 (Cracknell, 2010). Health services face major challenges in obesity, chronic disease (cardiovascular, diabetes) and dementia and promoting healthy ageing is a major concern internationally. Physical activity is a powerful mitigating factor in chronic disease (Nocon, Hiemann, Müller-Riemenschneider et al 2008; Pedersen and Saltin, 2006) and exercise is an effective treatment for heart and pulmonary diseases (Booth and Roberts 2008). Physically active men have a $20-30 \%$ reduced risk of premature death and $50 \%$ less chronic disease, but only a minority are active at the recommended level. Physical activity declines with age. Only 32\% of 55-64 year old men meet the exercise target and $9 \%$ aged 75 or over. Given the importance of physical activity Blair and Morris (2009) conclude that the key challenge is to create new opportunities for older adults to exercise. Walking football may represent such an opportunity. 
The health benefits of football are well established. Krustrup, Dvorak, Junge and Bangsbo (2010) conclude that football is a broad spectrum exercise that improves cardio-vascular and musculo-skeletal fitness and reduces the risk of cardiovascular disease, falls and fractures. Krustrup, Randers, Andersen et al (2013) found football to be effective in treating arterial hypertension. Krustrup, Aagaard, Nybo et al (2010) reported that small-sided football, regardless of age, produced high aerobic activity with marked improvements in blood pressure, fat oxidation, muscle capillarization and aerobic power and postural balance and rapid muscle force was markedly better for 70-year old footballers than for controls and as good as nonplaying 30-year olds. Nielsen, Wikman, Jensen et al (2014) report that football has a positive impact on social relations, enjoyment and on exercise continuation.

Exercise has shown an impact on cognitive function in older adults (e.g. Colcombe \& Kramer, 2003). Exercise enhances neurogenesis, the health and survival of neurons, the number of synapses and neuroplasticity (Smith, 2013). Colcombe, Erickson, Scalf et al (2006) found increased grey and white matter in the prefrontal cortex after six months of cardiovascular fitness training with older adults. This links improvement in executive function with actual brain changes in the area most associated with executive function. However the impact specifically of walking football has not been examined.

Colcombe, Kramer, Erickson et al (2004) found cardiovascular exercise increased aerobic fitness and Functional Magnetic Resonance Imaging (FMRI) of brain activity during the cognitive task showed a higher rate of activation in the prefrontal cortex. Their research did not identify how much physical activity is needed to address cognitive decline, however Masley, Roetzheim and Gualtieri (2009) demonstrated that moderate and high doses of exercise improved executive function. In line with Colcombe, Kramer, Erickson et al (2004), attention and cognitive flexibility displayed the largest advances as a result of increased cardiovascular fitness suggesting that exercise even at moderate intensity may inhibit cognitive decline.

During exercise neurogenesis acts on neuronal stem cells in the hippocampus, recruiting new neurons from cells with neurogenic potential (Van Praag, Kempermann \& Gage, 2000). Exercise encourages neuron formation, grey matter and brain-derived neurotrophin factor (BDNF), a protein that keeps neurons alive and increases the growth of neurons and synapses in the area of the hippocampus where new information is stored. Vaughan, Wallis, Polit et al (2014) found that football improved cardio-vascular and muscular-skeletal fitness and affected aspects of brain function that are important for performance in competitive situations demanding skill and judgement. Krustrup, Aagaard, Nybo et al (2010) found that small-sided football produced high aerobic activity with mean heart rates of $80-85 \%$ of age-related maxima. Elbe, Strahler, Krustrup, Wikman \& Stelter (2010) found that players experienced low-to-moderate levels of perceived exertion and high levels of 'flow,' (Csikszentmihalyi, 1990) a state in which involvement in an activity reduces awareness of fatigue, with low levels of worry and moderate perception of exertion. Thus football combines weight-bearing aerobic activity, 
engrossing play leading to 'flow' and lowered perception of physical exertion, and social interaction intrinsic to a team sport. However the physical demands of football make it increasingly unsustainable with age as capacity and flexibility decline and recovery times lengthen and older players withdraw when no longer welcomed by competitive teams. Although football is popular and adaptable few opportunities exist for older people to participate on their own terms.

Walking football has emerged recently in the UK. It is mostly small-sided, mostly recreational football played within semi-formal groups rather than formal teams, overwhelmingly by older men, at or near walking pace. The pitch, number of players, strictness of the walking rule and the tackling allowed, if any, may all vary. The defining distinction is that it is walking football. Thus it can be played by the less mobile who can still use their skill and experience to position themselves, create space, see openings, control the ball, pass and move, draw defenders, feint, volley, dribble, pass, shoot, and enjoy the game. It limits the influence of fitter, more mobile players, it slows the player but not necessarily the play. Make the ball do the work as the traditional injunction goes. Walking football also acts as a brand that proclaims the game to be for the older and less mobile. This branding, as much as the walking rule itself, may be behind its growth.

Football generally is healthy exercise, but is walking football rewarding, beneficial and sustainable for older adults and do the general health benefits of football apply to it? Little research into walking football has been published however Hubball and Reddy (2015) found that competitive walking football was enjoyable, could be played more frequently with less strain than regular football and the emphasis on passing had team-building benefits for Canadian high performance veteran football players. The present study arises from the creation of a walking football group to enable players who had withdrawn from recreational football to return. It is inspired by the grass-roots growth of walking football in the UK.

\section{Aims}

A 12-week walking football trial to investigate:

1) The experience of older adults playing walking football every week, is it sustainable and rewarding

2) The intensity and locomotor pattern of walking football

3) The scale and nature of walking football health benefits

4) Possible cognitive benefits of playing walking football through measures of processing speed, selective and divided attention and updating and inhibition components of executive function.

\section{Method}

\section{Design and measures}




\section{Experience and meaning}

Six individual semi-structured interviews were conducted by the fourth author (NC) who used interpretative phenomenological analysis (IPA) methodology to analyse the transcripts (Smith and Eatough, 2006). IPA is idiographic and has been widely used since the late 1990s (Forrester, 2010). It draws on a range of phenomenological thinking and attempts to engage with lived experience on its own terms (Smith, 2015). An adapted Groningen Enjoyment Questionnaire (GEQ, Stevens, Moget, de Greef, Lemmink and Rispens, 2000) was administered at the end of the study.

\section{Intensity and locomotor pattern}

Participants wore Polar T34 belts (Polar Electro Oy, Kempele, Finland) to measure heart rate and portable 15-Hz GPS trackers (SPI Pro X, GPSports, Canberra, Australia) to measure distance travelled. The Borg Rating of Perceived Exertion (RPE) Scale (Borg, 1970) was also completed each week.

\section{Health and fitness}

At pre- and post-study morning fasting blood test appointments, measurements were made of:

- Postural balance

- Blood pressure (systolic, diastolic, and mean arterial blood pressure)

- Resting heart rate

- Weight

- BMI

- Body composition

- Metabolic age

- Cholesterol

- Blood sugar

- Markers for bone formation

To examine whether the intervention had an impact on the health and fitness indices, each measure was subjected to a repeated measures analysis of variance with group as a between-participants factor and before versus after 7-12 weeks play as a within-participants factor. A p-value of 0.05 was selected and means, standard deviations and main effects of group, time and group $x$ time interactions are displayed in Table 1 . The group $x$ time interventions indicate whether one group changed more than the other over time. Power analyses suggested that 34 participants per group would be appropriate for a medium effect size and power of 0.80 , and so this group is underpowered. Nevertheless, data were examined as a demonstration of effects for this pilot.

\section{Executive function}


At the same appointments two computer-administered tests, detailed below, were administered.

\section{Random Number Generator (RNG) Task}

Participants completed an objective measure of executive function with one task that measured both inhibition and updating selection (Towse \& Neil, 1998). The three measures that were selected for analysis were RNG index, Adjacency (A) and Redundancy (R). The RNG index highlights how often certain numbers in pairs or triplets have occurred. A low score on the RNG index indicates there is no pattern and the string of numbers is random (good score). This highlights how well an individual's executive function is inhibiting patterns. The adjacency (A) score indicates when the numbers appear in a sequence, highlighting the participant's ability to inhibit well-learnt patterns. (A) score measures either ascending, descending or combined scores. Combined scores were used. A low combined score is a good score highlighting randomness (Miyake, Friedman, Emerson, Witzki, et al, 2000). The redundancy score ( $R$ ) indicates how often each number occurred when compared to others. If a number occurred more frequently this gives a higher score indicating poor randomness. This is a measure of the updating factor (Towse and Neil, 1998). A lower score on each measure indicates good executive function.

\section{Useful Field of View (UFOV) Task}

The Useful Field of View (UFOV) was used to measure the extent of the visual field from which information is extracted in a single glance (Sanders, 1970). The UFOV task compromises of central identification and peripheral localization tasks assessing processing speed, divided attention and selective attention (Ball and Owsley, 1993). The first subtest assessing processing speed consists of fixating gaze on the blank box in the middle of the screen. A car or truck will appear in middle of the box and disappear, participants will then be asked if they saw a car or a truck and respond using the mouse. The exposure time of the central stimulus reduces until the participants shortest perceptual threshold is determined. The second subtest assesses divided attention and consists of a car or truck being presented in the centre of the screen, and another object (car) being presented in the periphery. Participants are asked to respond to which object they saw in the centre of the screen and indicate where the target appeared in the periphery using the mouse. The third subtest assesses selective attention is identical to task two however, the car displayed in the periphery is embedded in a field of 47 triangles. Participants will be asked to respond to which object they saw in the center of the screen and where the target object appeared in the periphery using the mouse. A lower score on each of the three subtests in the UFOV task indicates better performance (faster detection) on information processing and attention amongst participants (Edwards, Ross, Wadley, Clay et al., 2006). 
Similar analyses to those described above for health and fitness were employed to examine changes in processing speed, selective and divided attention and the updating and inhibition components of executive function. Outliers were identified for the UFoV measures, suggesting that some participants had not understood the instructions. The removal of outliers was based on performance of more than 2 SDs worse (greater) than the mean. One experimental group participant was removed from each analysis resulting in the data becoming normally distributed. The data is displayed in Table 2.

\section{Participants}

Twenty participants between 50 and 65 years were recruited through a snowball procedure starting with staff and a patient panel. Names were drawn out of a hat and allocated alternately to two groups with seeding used to keep a couple together against two female participants. A coin toss decided which group was which. No inclusion criteria other than age was specified. Participants were advised to assure themselves of their fitness to participate before doing so. Written informed consent was obtained. Ethical approval was granted by the ethics committee of the School of Life and Health Sciences, Aston University.

\section{Facilities, equipment, procedure}

The intervention consisted of a one-hour (warm-up, 45-50 minutes play) small sided game of walking football, normally five-a-side, played once a week for 12 weeks. Younger players were recruited to make up numbers as necessary. An outdoor, floodlit, fully netted, rubber crumb artificial grass pitch was used. Bibs were allocated to create sides.

At pre and post-study appointments a Eurofit compliant balance beam was used to assess postural balance. Blood pressure and resting heart rate (mean of three readings) were measured using a semi automatic inflatable upper-arm-cuff blood pressure monitor (Lloyds Pharmacy KD-322). Weight, BMI, body composition and metabolic age were measured using a Tanita BC601 Innerscan Segmental Body Composition Monitor Scale. Finger-prick blood samples were taken to analyse fasting blood levels of total cholesterol, glucose and Alkaline Phosphatase using the Reflotron apparatus. (Reflotron Check strip was used to check the optical system of the Reflotron Plus apparatus weekly. The whole system was checked with control sera (Reflotron Precinorm U) monthly and CV between these tests were less than $9 \%$ during our analysis).

\section{Results}

The experimental group (one female) had a mean age of 61.1 years and the control group (two females) of 58.3 years. Nine control group and eleven experimental 
participants are included in the results each experimental participant having played at least seven of 12 games (mean 9.4, mode 11).

\section{Experience and meaning}

\section{1. qualitative data}

Themes identified through interview analysis are i) attitudes towards walking football, ii) experience of participation, iii) impact of participation. Names are pseudonyms.

\section{Attitudes towards walking football}

A common concern for participants was whether they would be capable of playing walking football.

"I was definitely concerned about my knee, whether my knee would stand up t... ... side-footing the ball ..." (Scott)

"I ...fractured my tibia right at the knee joint and so that has curtailed a lot of my sport .... walking football appealed .... w wasn't running but I could still play football." (Julia)

There was initial scepticism about walking football and the players it would attract.

"I was bit dubious at first... would they be too good or too crap? ...if they were fifty-year old blokes and they were really fit and they'd just stopped playing, perhaps would they be too good for ya? Or would they be blokes who had never played and I'd think to meself 'Oh God, this is too boring'." (Brian)

\section{Experience of walking football}

Participants tended to run at first and refereeing intervention was necessary. Once adapted players found that walking football preserved much of the experience of playing football but at a less physical level. Despite being at walking pace it remained quite a brisk experience and players worked up a sweat. Weight and accuracy of pass and movement off the ball were at a premium. Most players concerned about pre-existing injuries found few problems but one player had to withdraw with an old injury and three others missed games with injuries. Pain and stiffness was common at first.

"My knee was a bit stiff but it hadn't blown up in the way that it does when I play squash...." (Julia) 
"... immediately afterwards, amazed that I'd done it and then for about the next four or five days, thinking I was crazy to have done it because every muscle in my arms, legs, chest, hips, back ached!" (Nigel)

"God that first day! The next morning, my legs , ....y'know you're walking ...about two and a half kilometres." (Julia)

Interviewees found walking football enjoyable and preferred it to alternatives.

"...going to the gym is very boring, ....and it's so monotonous. ...if anyone said I could kick a football round [again] I'd have thought there were mad. But it, it's really good. ...it's so much better than just sitting on a bike." (Matthew)

\section{The impact of participation in walking football}

Returning to football was exciting and enjoyable.

"I suppose it's the adrenaline, isn't it? It gives you a high. You're gonna go out and do something you thought you'd NEVER EVER get near doing again." (Nigel)

Many felt more confident and proud that they could compete.

"I just feel more confident as a person. ...I'll take more things on... I won't be scared to do it because you think 'well, if I can do this at my age...' I feel more confident just walking around the street to be quite honest." (Matthew)

Walking football allowed players to meet people, it paved the way for new friendships to develop.

"...helps with the camaraderie, ... and it gets you out, gets you involved." (John)

Participants also felt that walking football had improved their health and wellbeing.

\section{2 quantitative data}

An adapted Groningen Enjoyment Questionnaire (Stevens, Moget, de Greef, Lemmink and Rispens, 2000) administered at the end of study produced a mean score of $65.1 / 70$ indicating high enjoyment.

Overall walking football was experienced as an authentic form of football and enjoyable enough to participate in regularly. 


\section{Intensity and locomotor pattern}

Heart rate (HR) during play was a mean of $76 \%$ of age or match-predicted maximum heart rate (HRmax) $(S D=6.65)$.

A mean distance of 2386 metres per player/game was covered ( $S D=308.76)$. The mean Borg RPE figure was 13.31 (range 9-17 on a scale of 0-20) where a score of 13 = 'Somewhat hard' with the descriptor 'brisk walking or other activities that require moderate effort and speed your heart rate and breathing but don't make you out of breath.'

\section{Health and fitness - results and statistical analysis}

Table 1 about here

Only the measures for blood pressure improved more for players than for controls. This was was significant $(p<.05)$ for mean arterial blood pressure. There were other overall positive effects (e.g. for cholesterol and balance) for both groups.

\section{Executive function - results and statistical analysis}

Table 2 about here

Data indicate that the football group did not improve more than the control group on any of the measures in Table 2, but there were some improvements for both groups, presumably as an effect of practice (selective attention). However participants got worse at the random number generation task. The control participants showed more improvement than the football group at processing speed, however this seems to be an artefact of the initially poor performance of the control group. Controlling for initial performance, there was no difference in the Time 2 measures $(F(1,18)=1.42, p>0.05)$.

Relationships between change in the physiological measures and change in the cognitive measures was examined. The only significant relationships were between change in $\mathrm{BMI}$ and in processing speed and selective attention ( $r=-.55$ and $r=-.57$ respectively, both $\mathrm{p}<0.05$ ). Although $\mathrm{BMI}$ did not change significantly over the whole sample, change was associated with improved performance on these measures.

\section{Discussion}

This study shows that walking football for older adults may be sustainable. It is not too physically demanding and it is engaging to play. Sceptical interest turned to 
enthusiasm once play began. Players initially found avoiding running difficult but later play felt natural and involving. Seven of the experimental participants have continued to play.

Little impact on health and fitness was found. Unlike Arnold, Bruce-Low and Sammut (2015) who report that twelve weeks of a two-hour weekly training session with ten males in their mid sixties positively altered a range of anthropometic and fitness factors and conclude that walking football is safe and efficacious exercise. Only the measures for blood pressure improved more for players than for controls in the study reported here. Arnold, Bruce-Low and Sammut used multiple short 5-a-side games for two hours once per week, players were thus playing for up to twice as long. This may account for the differing findings, although measures used also differed. One hour per week may be an inadequate exercise dose. It falls below the UK National Health Service recommendation of 150 minutes of moderate aerobic activity or 75 minutes of vigorous aerobic activity (defined as running or a game of singles tennis, NHS 2016) per week. It also is less than the American College of Sports Medicine (ACSM) position stand recommends (Pollock, Gaesser, Butcher, Després, Dishman, Franklin and Garber, 1998).

Intensity and locomotor data suggest that walking football falls between moderate and vigorous activity. Heart rate (HR) during play was $76 \%$ of age or match-predicted maximum heart rate (HRmax) and in comparison Krustrup, Aagaard, Nybo et al (2010) report HR in their study of small-sided regular football as $80-85 \%$ of HRmax. Pollock, Gaesser, Butcher et al (1998) note that although age is not a limiting factor to exercise in itself, 'a more gradual approach at older ages seems prudent' and that 'many health benefits from physical activity can be achieved at lower intensities of exercise if frequency and duration of training are increased appropriately' (p. 50). At the start of the study the concern was that regular football was too vigorous for older adults and a lower intensity alternative was offered that would be potentially sustainable and encourage lifestyle change and long term commitment to physical activity. Exercise of moderate intensity is beneficial and the key challenge is to find new opportunities for older adults to exercise as Blair and Morris (2009) suggest. We conclude that walking football should be undertaken for more than one hour once per week and that its sustainability for older adults at this level needs further investigation.

No improvement was evident in executive function. However participants were tested on all the physical and cognitive outcomes at the same appointment which included a fasting blood test. Cognitive function can be affected by low blood sugar which may not only reduce performance (e.g. Heller and Macdonald, 1996), but also increase within-person variability. While this issue would affect both control and football players it is a potential source of unreliable cognitive measures.

The relationships between change in the physiological measures and the change in the cognitive measures revealed reliable relationships between change in BMI and both processing speed and selective attention, despite there being no significant overall group change in these measures. The majority of participants were 
moderately overweight ( $\mathrm{BMI}>25)$ and this effect, although possibly incidental, may indicate that where there was a reduction in $\mathrm{BMI}$ it may have had a positive impact on these aspects of the speeded processing of visual information.

Overall we suggest that walking football is feasible and enjoyable for older men and promotes social contact. Possible health and cognitive effects deserve further investigation. Older adults do not exercise enough and Blair and Morris (2009) note the need to find new forms of exercise for older adults to engage in.

\section{Limitations}

Limitations include lack of power, too few participants to control for frequency of attendance, and no control over other aerobic activity. Cognitive testing took place after fasting and low glucose affects these measures. Time of year (winter) is another variable. Most participants were experienced footballers, some had not played before but this information was not colated for this study, nor was other physical activity recorded or controlled or any medication being taken rcorded.

\section{Further research}

Larger and longer studies into the health, cognitive and social benefits of walking football at greater frequency than one hour per week would seem desireable. It may attract parts of the population that may be hard to reach with other exercise initiatives, men generally for example, especially those from lower socio-economic backgrounds. Further research into these aspects would be desirable as would research into its attraction for women and specific populations, including older age segments. It also prompts research into other sports adapted for older players. Comparitive research into the experience of playing walking football in comparison with other forms of football would also be interesting.

\section{References}

Andersen, L. J., Hansen, P. R., Søgaard, P., Madsen, J. K., Bech, J., \& Krustrup, P. (2010). Improvement of systolic and diastolic heart function after physical training in sedentary women. Scandinavian journal of medicine \& science in sports, 20 (s1), 5057.

Arnold, J. T., Bruce-Low, S. \& Sammut, L. (2015). The impact of 12 weeks walking football on health and fitness in males over 50 years of age. BMJ Open Sport \& Exercise Medicine. 1:e000048.doi:10.1136/ 
Ball, K. \& Owsley, C. (1993). The useful field of view test: a new technique for evaluating age-related declines in visual function. Journal of the American Optometric Association. 64 (1), 71-79.

Blair, S. N., \& Morris, J. N. (2009). Healthy hearts and the universal benefits of being physically active: Physical activity and health. Annals of Epidemiology, 19 pp. 253256.

Borg, G. (1970). Perceived exertion as an indicator of somatic stress. Scandinavian journal of rehabilitation medicine 2 (2): 92-98

Booth, F. W. \& Roberts, C. K. (2008) Linking performance and chronic disease risk: indices of physical performance are surrogates for health. British Journal of Sports Medicine 42, pp. 950-952.

Broman, A. T., West, S. K., Muñoz, B., Bandeen-Roche, K., Rubin, G. S., Turano, K. A. (2004). Divided visual attention as a predictor of bumping while walking: The Salisbury eye evaluation. Investigative Ophthalmology \& Visual Science, 45 (9), 29552960.

Colcombe, S., \& Kramer, A. F. (2003). Fitness effects on the cognitive function of older adults a meta-analytic study. Psychological science, 14(2), 125-130.

Colcombe, S. J., Kramer, A. F., Erickson, K. I., Scalf, P., McAuley, E., Cohen, N. J., et al. (2004). Cardiovascular fitness, cortical plasticity, and aging. Proceedings of the National Academy of Science. 101(9): 3316-21

Colcombe, S. J., Erickson, K. I., Scalf, P. E., Kim, J. S., Prakash, R., McAuley, E., Elavsky, S., Marquex, D. X., Hu, L., \& Kramer, A. F. (2006). Aerobic exercise training increases brain volume in ageing humans. Journal of Gerontology and biological science, medical science, (61), 1166-1170.

Cracknell, R. (2010). The ageing population. House of Commons library research, (1), 44-45.

Csikszentmihalyi, M. (1990). Flow: The Psychology of Optimal Experience. Harper Perennial, New York.

Dommes, A., \& Cavallo, V. (2011). The role of perceptual, cognitive, and motor abilities in street-crossing decisions of young and older pedestrians. Ophthalmic and Physiological Optics, 31(3), 292-301.

Edwards, J. D., Ross, L. A., Wadley, V. G., Clay, O. J., Crowe, M., Roenker, D. L. \& Ball, K. K. (2006). The useful field of view test: Normative data for older adults. Archives of Clinical Neuropsychology. 21 (4), 275-286. 
Elbe, A-M., Strahler, K., Krustrup, P., Wikman, J. \& Stelter, R. (2010). Experiencing flow in different types of physical activity intervention programs: three randomized studies. Scandinavian Journal of Medicine and Science in Sports. 20, Special issue; football for health, pp. 111-117.

Forrester, M.A. (2010). Doing Qualitative research in psychology. London, Sage.

Heller, S. R. \& Macdonald, I. A. (1996). The measurement of cognitive function during acute hypoglycemia: experimental limitations and their effect on the study of hypoglycemia unawareness. Diabetic Medicine 13: 607-615, 1996.

Hubball, H. \& Reddy, P. (2015). Impact of Walking Football: Effective Team Strategies for High Performance Veteran Players. Journal of Sports Pedagogy and Physical Education. 6 (1) 13-27.

Krustrup, P., Aagaard, P., Nybo, L., Petersen, J., Mohr, M. \& Bangsbo, J. (2010). Recreational football as a health promoting activity: a topical review. Scandinavian Journal of Medicine and Science in Sports. 20, Special issue; football for health, pp.113.

Krustrup, P., Dvorak, J., Junge, A. \& Bangsbo, J. (2010). Executive summary: The health and fitness benefits of regular participation in small-sided football games. Scandinavian Journal of Medicine and Science in Sports. 20, Special issue; football for health, pp.132-135.

Krustrup, P., Randers, M. B., Andersen, L. J., Jackman, S. R., Bangsbo, J. \& Hansen, P. R. (2013). Soccer improves fitness and attenuates cardiovascular risk factors in hypertensive men. Medicine \& Science in Sports \& Exercise. 45(3): 553-560.

Masley, S., Roetzheim, R., \& Gualtieri, T. (2009). Aerobic Exercise Enhances Cognitive Flexibility. Journal of Clinical Psychology in Medical Settings. 16(2):186-93

Miyake, A., Friedman, N. A., Emerson, M. J., Witzki, A. H., Howerter, A. \& Wager, T. D. (2000). The Unity and Diversity of Executive Functions and Their Contributions to Complex "Frontal Lobe" Tasks: A Latent Variable Analysis. Cognitive Psychology, 41 (1), 49-100.

Neilsen, G., Wikman, J. M., Jensen, C. J., Schmidt, J. F., Gliemann, L. \& Andersen, T. R. (2014). Health Promotion: The impact of beliefs of health benefits, social relations and enjoyment on exercise continuation. Scandinavian Journal of Medicine \& Science in Sports (24), 66-75.

NHS physical activity guidelines for adults, (2016). http://www.nhs.uk/Livewell/fitness/Pages/physical-activity-guidelines-foradults.aspx Accessed 22/06/2016

Nocon, M., Hiemann, T., Müller-Riemenschneider, F., Thalau, F., Roll, S., \& Willich, S. 
N. (2008). Association of physical activity with all-cause and cardiovascular mortality: a systematic review and meta-analysis. European Journal of Cardiovascular Prevention \& Rehabilitation, 15(3), 239-246.

Pedersen, B. K. \& Saltin, B. (2006). Evidence for prescribing exercise as therapy in chronic disease. Scandinavian Journal of Medicine and Science in Sports. 16, Special issue; football for health, pp.3-63.

Pollock, M.L., Gaesser, G.A., Butcher, J.D., Després, J-P., Dishman, R.K., Franklin, B.A. \& Garber, C.E. (1998). American College of Sports Medicine Position Stand on The Recommended Quantity and Quality of Exercise for Developing and Maintaining Cardiorespiratory and Muscular Fitness, and Flexibility in Adults. Medicine and Science in Sports and Exercise, 30 (6), 975-991.

Sanders, A. F. (1970). Some aspects of the selective process in the functional visual field. Ergonomics, 13 (1), 101-17.

Smith, G. S. (2013). Aging and neuroplasticity. Dialogues in Clinical Neuroscience, 15(1):3-5.

Smith, J. A. (2015). Learning from the lifeworld. The Psychologist, 28, 8, 644-5

Smith, J. A. \& Eatough, V. (2006). Interpretative Phenomenological Analysis. In: G. Breakwell, S. Hammond, C. Fife-Schaw \& J. A. Smith, (Eds.) Research methods in Psychology ( $3^{\text {rd }}$ edn.) London, Sage.

Stevens, M., Moget, P., de Greef, M. H. G., Lemmink, K. A., \& Rispens, P. (2000). The Groningen Enjoyment Questionnaire: A measure of enjoyment in leisure-time physical activity. Perceptual and Motor Skills, 90 (2), 601-604.

Towse, J. N. \& Neil, D. (1998). Analyzing human random generation behavior: A review of methods used and a computer program for describing performance. Behaviour Research Methods, Instruments \& Computers, 30 (4), 583-91.

van Praag, H., Kempermann, G., \& Gage, F. H. (2000). Neural consequences of environmental enrichment. Nature Reviews Neuroscience. 1(3):191-8.

Vaughan, S., Wallis, M., Polit, D., Steele, M., Shum, D. \& Morris, N. (2014). The effects of multimodal exercise on cognitive and physical functioning and brainderived neurotrophic factor in older women: a randomised controlled trial. Age and Ageing, (0), 1-6. 
Table 1: Physiological measurements for the football and control groups before and after the 12 week intervention. Football $(\mathrm{N}=11)$, Control $(\mathrm{N}=9)$.

\begin{tabular}{|c|c|c|c|c|c|c|}
\hline $\begin{array}{l}\text { Physiological } \\
\text { Variables }\end{array}$ & Group & $\begin{array}{l}\text { Time } 1 \\
\text { Mean } \\
\text { (SD) }\end{array}$ & $\begin{array}{l}\text { Time } 2 \\
\text { Mean } \\
\text { (SD) }\end{array}$ & $\begin{array}{l}\text { Overall } \\
\text { Group } \\
\text { effect (F- } \\
\text { ratio) }\end{array}$ & $\begin{array}{l}\text { Overall } \\
\text { before-after } \\
\text { effect (F- } \\
\text { Ratio) }\end{array}$ & $\begin{array}{l}\text { Group } x \text { time } \\
\text { interaction (F- } \\
\text { ratio) }\end{array}$ \\
\hline Systolic BP & Football & \begin{tabular}{|l|}
140.3 \\
$(14.4)$ \\
\end{tabular} & $\begin{array}{l}131.24 \\
(17.4) \\
\end{array}$ & $\begin{array}{l}4.67 \\
(p=.044)\end{array}$ & $0.35(p=.56)$ & $4.07(p=.059)$ \\
\hline Systolic BP & Control & $\begin{array}{l}120.1 \\
(17.2)\end{array}$ & $\begin{array}{l}125.00 \\
(12.6)\end{array}$ & & & \\
\hline Diastolic BP & Football & $\begin{array}{l}87.6 \\
(9.4) \\
\end{array}$ & $86.3(8.4)$ & $\begin{array}{l}4.96 \\
(p=.039)\end{array}$ & $1.06(p=.32)$ & $2.79(p=.11)$ \\
\hline Diastolic BP & Control & $\begin{array}{l}75.9 \\
(10.7) \\
\end{array}$ & $81.4(9.3)$ & & & \\
\hline \multirow[t]{2}{*}{$\begin{array}{l}\text { Mean arterial } \\
\text { pressure }\end{array}$} & Football & $\begin{array}{l}104.1 \\
(9.3)\end{array}$ & $\begin{array}{l}100.3 \\
(9.1)\end{array}$ & $\begin{array}{l}6.14 \\
(p=.02)\end{array}$ & $0.13(p=.73)$ & $5.21(p=.035)$ \\
\hline & Control & $\begin{array}{l}89.7 \\
(12.3)\end{array}$ & $95.0(8.8)$ & & & \\
\hline Weight (Kg) & Football & $\begin{array}{l}83.80 \\
(12.94) \\
\end{array}$ & $\begin{array}{l}83.28 \\
(13.15) \\
\end{array}$ & $\begin{array}{l}0.49 \\
(p=.49)\end{array}$ & $0.27(p=.61)$ & $1.11(p=.31)$ \\
\hline Weight (Kg) & Control & $\begin{array}{l}78.89 \\
(16.68)\end{array}$ & $\begin{array}{l}79.06 \\
(15.99)\end{array}$ & & & \\
\hline $\mathrm{BMI}$ & Football & $\begin{array}{l}27.91 \\
(3.22)\end{array}$ & $\begin{array}{l}27.81 \\
(3.37)\end{array}$ & $\begin{array}{l}0.01 \\
(p=.92)\end{array}$ & $0.04(p=.85)$ & $0.80(p=.38)$ \\
\hline BMI & Control & $\begin{array}{l}27.60 \\
(4.46)\end{array}$ & $\begin{array}{l}27.67 \\
(4.30)\end{array}$ & & & \\
\hline \multirow[t]{2}{*}{ Global fat (\%) } & Football & $\begin{array}{l}27.1 \\
(7.3) \\
\end{array}$ & $\begin{array}{l}30.9 \\
(19.6) \\
\end{array}$ & $\begin{array}{l}0.26 \\
(p=.62)\end{array}$ & $0.45(p=.51)$ & $0.38(p=.55)$ \\
\hline & Control & $\begin{array}{l}31.1 \\
(5.7)\end{array}$ & $31.3(7.5)$ & & & \\
\hline \multirow[t]{2}{*}{ Visceral Fat } & Football & $\begin{array}{l}13.36 \\
(3.83) \\
\end{array}$ & $\begin{array}{l}13.00 \\
(3.87) \\
\end{array}$ & $\begin{array}{l}0.68 \\
(p=.42)\end{array}$ & $0.42(p=.52)$ & $1.50(p=.24)$ \\
\hline & Control & $\begin{array}{l}11.6 \\
(4.7) \\
\end{array}$ & $11.7(4.7)$ & & & \\
\hline \multirow[t]{2}{*}{$\begin{array}{l}\text { Cholesterol } \\
(\mathrm{mmol} / \mathrm{l})\end{array}$} & Football & $\begin{array}{l}4.1 \\
(1.1)\end{array}$ & $\begin{array}{l}3.6 \\
(0.7)\end{array}$ & $\begin{array}{l}0.46 \\
(p=.51)\end{array}$ & $\begin{array}{l}12.97 \\
(p=.002)\end{array}$ & $1.92(p=.18)$ \\
\hline & Control & $\begin{array}{l}4.6 \\
(1.3)\end{array}$ & $3.0(0.6)$ & & & \\
\hline \multirow[t]{2}{*}{$\begin{array}{l}\text { Alkaline } \\
\text { Phosphate } \\
\text { (U/I) }\end{array}$} & Football & $\begin{array}{l}37.89 \\
(9.28)\end{array}$ & $\begin{array}{l}47.05 \\
(19.21)\end{array}$ & $\begin{array}{l}0.62 \\
(p=.44)\end{array}$ & $2.93(p=.10)$ & $0.10(p=.76)$ \\
\hline & Control & $\begin{array}{l}45.21 \\
(20.47)\end{array}$ & $\begin{array}{l}51.54 \\
(25.13)\end{array}$ & & & \\
\hline \multirow[t]{2}{*}{ Glucose } & Football & $\begin{array}{l}4.3 \\
(1.1) \\
\end{array}$ & $4.6(1.2)$ & $\begin{array}{l}0.71 \\
(p=.41)\end{array}$ & $2.28(p=.15)$ & $0.46(p=.51)$ \\
\hline & Control & $\begin{array}{l}4.4 \\
(1.2)\end{array}$ & $5.3(2.1)$ & & & \\
\hline Balance & Football & $9(3)$ & $6(3)$ & 0.05 & 11.67 & $0.04(p=.84)$ \\
\hline
\end{tabular}




\begin{tabular}{|c|c|c|c|c|c|}
\hline $\begin{array}{l}\text { (number of } \\
\text { "touches" in } \\
\text { flamingo test) }\end{array}$ & & & & $(p=.82)$ & $(p=.003)$ \\
\hline Balance & Control & 9 (3) & 7 (2) & & \\
\hline
\end{tabular}

Table 2

Cognitive measurements for the football and control groups before and after the 12 week intervention ( $\mathrm{N}=10$ Football, 9 Control).

\begin{tabular}{|c|c|c|c|c|c|c|}
\hline $\begin{array}{l}\text { Cognitive } \\
\text { measures }\end{array}$ & Group & $\begin{array}{l}\text { Time } 1 \\
\text { Mean (SD) }\end{array}$ & $\begin{array}{l}\text { Time } 2 \\
\text { Mean (SD) }\end{array}$ & $\begin{array}{l}\text { Overall } \\
\text { Group effect } \\
\text { (F-ratio) }\end{array}$ & $\begin{array}{l}\text { Overall } \\
\text { before- } \\
\text { after effect } \\
\text { (F-ratio) }\end{array}$ & $\begin{array}{l}\text { Group } x \\
\text { time } \\
\text { interaction } \\
\text { (F-ratio) }\end{array}$ \\
\hline \multirow{2}{*}{$\begin{array}{l}\text { Processing } \\
\text { speed }\end{array}$} & Football & $18.50(2.55)$ & $19.80(3.52)$ & $0.78(p=.39)$ & $1.95(p=.18)$ & $5.27(p=.04)$ \\
\hline & Control & $23.00(7.26)$ & $17.67(2.00)$ & & & \\
\hline \multirow[t]{2}{*}{$\begin{array}{l}\text { Divided } \\
\text { attention }\end{array}$} & Football & $\begin{array}{l}26.91 \\
(16.99)\end{array}$ & $24.91(9.42)$ & $1.50(p=.24)$ & $0.18(p=.68)$ & $<.1, p=.98$ \\
\hline & Control & $23.00(8.93)$ & $21.25(5.60)$ & & & \\
\hline \multirow[t]{2}{*}{$\begin{array}{l}\text { Selective } \\
\text { attention }\end{array}$} & Football & $\begin{array}{l}180.63 \\
(87.88) \\
\end{array}$ & $\begin{array}{l}123.55 \\
(49.13) \\
\end{array}$ & $\begin{array}{l}7.45 \\
(p=.014)\end{array}$ & $\begin{array}{l}12.21 \\
(p=.003)\end{array}$ & $1.44(p=.25)$ \\
\hline & Control & $\begin{array}{l}101.63 \\
(24.21) \\
\end{array}$ & $\begin{array}{l}73.75 \\
(28.14) \\
\end{array}$ & & & \\
\hline \multirow[t]{2}{*}{ R (updating) } & Football & $1.24(0.63)$ & $\begin{array}{l}2.07 \\
(0.61) \\
\end{array}$ & $\begin{array}{l}0.44 \\
(p=.44)\end{array}$ & $\begin{array}{l}7.83 \\
(p=.013)\end{array}$ & $\begin{array}{l}0.071 \\
(p=.92)\end{array}$ \\
\hline & Control & $\begin{array}{l}1.52 \\
(0.70) \\
\end{array}$ & $\begin{array}{l}2.31 \\
(1.81)\end{array}$ & & & \\
\hline \multirow[t]{2}{*}{$\begin{array}{l}\text { Adjacency } \\
\text { (inhibition) }\end{array}$} & Football & $\begin{array}{l}27.32 \\
(12.18) \\
\end{array}$ & $\begin{array}{l}48.98 \\
(12.92) \\
\end{array}$ & $3.00(p=.10)$ & $\begin{array}{l}13.83 \\
(p=.002)\end{array}$ & $2.90(p=.11)$ \\
\hline & Control & $\begin{array}{l}41.95 \\
(18.87) \\
\end{array}$ & $\begin{array}{l}50.00 \\
(7.71) \\
\end{array}$ & & & \\
\hline \multirow[t]{2}{*}{$\begin{array}{l}\text { RNG } \\
\text { (inhibition) }\end{array}$} & Football & $\begin{array}{l}0.28 \\
(0.08)\end{array}$ & $0.29(0.06)$ & $\begin{array}{l}<0.1 \\
(p=0.98)\end{array}$ & $0.45(p=.51)$ & $1.16(p=.30)$ \\
\hline & Control & $\begin{array}{l}0.30 \\
(0.07)\end{array}$ & $0.27(0.06)$ & & & \\
\hline
\end{tabular}

